\title{
Trimethoprim-sulphamethoxazole in urinary tract infection due to Streptococcus faecalis
}

\author{
B. CHATTOPADHYAY
}

\author{
From the Department of Bacteriology, Westminster Hospital Teaching Group, Queen Mary's \\ Hospital, Roehampton, London
}

SYNOPSIS In-vitro sensitivities were performed on 140 specimens of urine which grew Streptococcus faecalis of more than 100000 organisms/ml between March 1970 and February 1971. Although the combination of trimethoprim and sulphamethoxazole definitely appeared to be more effective than sulphonamide alone and as effective as ampicillin, its use for more than two weeks in 14 cases of uncomplicated urinary tract infection due to Streptococcus faecalis led to development of resistance. As in these cases organisms were resistant to sulphonamide to start with, it is suggested that the combination should be used in prolonged treatment only where the organisms are sensitive to both the individual antibiotics. Ampicillin is still the drug of choice in urinary tract infection due to Streptococcus faecalis. The alternative appears to be rotational therapy with other potent antibiotics.

The combination of trimethoprim and sulphamethoxazole has shown considerable promise in recent years in the treatment of urinary (Reeves, Faiers, Pursell, and Brumfitt, 1969; Grüneberg and Kolbe, 1969), respiratory (Hughes, 1969), and gastrointestinal (Brodie, MacQueen, and Livingstone, 1970; Kamat, 1970; Farid, Hassan, Wahab, Sanborn, Kent, Yassa, and Hathout, 1970) tract infections. It is effective against practically all the routinely encountered pathogens except Pseudomonas aeruginosa (Darrell, Garrod, and Waterworth, 1968). Trimethoprim and sulphamethoxazole exert a strongly synergic action, and the action is bactericidal, whereas that of a sulphonamide alone is only bacteriostatic (Bushby, 1969). Resistance to trimethoprim is fairly uncommon and the combination is often effective despite resistance to sulphonamide (British Medical Journal, 1969).

\section{Materials and Methods}

Out of a total of 140 strains, 96 were from inpatients at the hospital, 15 from outpatients, and 29 from local general practitioners. The specimens were collected from patients of all age groups and from both sexes. In-vitro sensitivities were performed on $5 \%$ lysed horse blood agar plates and they always included ampicillin $(25 \mu \mathrm{g})$, sulphonamide $(200 \mu \mathrm{g})$, trimethoprim $(2.5 \mu \mathrm{g})$, and trimethoprim-sulphamethoxazole $(25 \mu \mathrm{g})$ discs (Waterworth, 1969).

Received for publication 8 March 1972.
The plates were inoculated with the help of sterile cotton wool swab sticks which were dipped into urine and the excess drained off in order to get a uniform growth. The results were read after overnight incubation at $37^{\circ} \mathrm{C}$, the control strain used being $E$. coli (NCTC 10418). The sensitivity tests were repeated from pure culture whenever the inoculum appeared to be either too heavy or too light the next day.

The minimum inhibitory concentrations (MICs) of ampicillin, sulphonamide, and trimethoprim were determined against all the strains. The tube dilution technique was used for ampicillin. The MICs of sulphonamide and trimethoprim were estimated by the plate dilution technique with the use of $5 \%$ lysed horse blood agar plates (Darrell et al, 1968).

\section{CRITERION OF INFECTION}

The criterion of infection was a count exceeding 100000 organisms/ml in two consecutive urine specimens showing the same bacterial species.

CRITERION OF CURE

Examination of a specimen of urine from patient was carried out at one, two, and four weeks after starting treatment. Eradication of the organism was taken to be a cure.

\section{Results}

Before treatment the MICs of trimethoprim ranged 
between 0.25 and $1.0 \mu \mathrm{g} / \mathrm{ml}$, that of sulphonamide between 80 and $200 \mu \mathrm{g} / \mathrm{ml}$, and of ampicillin 1 and $2 \mu \mathrm{g} / \mathrm{ml}$ for all 23 isolates which later became resistant.

After treatment the MICs of trimethoprim and sulphonamide ranged between 8 and $16 \mu \mathrm{g} / \mathrm{ml}$, and more than $200 \mu \mathrm{g} / \mathrm{ml}$ respectively for the 14 resistant strains. Of the nine strains which became resistant to ampicillin, the MICs were between 10 and $18 \mu \mathrm{g} / \mathrm{ml}$.

Out of a total of 140 patients, 111 cases were followed up. The particular antibiotic used for each patient was decided by the clinicians concerned. It was found that 68 patients were treated with ampicillin $500 \mathrm{mg}$ eight hourly orally for seven days with nine failures, whereas 43 patients treated with trimethoprim-sulphamethoxazole, two tablets twice daily orally for five days with 14 failures. There was no significant difference between the two groups so treated. Out of a total of 68 patients, six had rash presumably due to ampicillin therapy, and the treatment was discontinued. They were subsequently treated with nitrofurantoin with good results.

\begin{tabular}{lll}
\hline Result & Ampicillin & $\begin{array}{l}\text { Trimethoprim- } \\
\text { sulphamethoxazole }\end{array}$ \\
\hline Number treated & 68 & 43 \\
Cured & 59 & 29 \\
Failed treatment & 9 & 14 \\
Rash & 6 & 1 \\
\hline
\end{tabular}

Table Results of treatment

Out of 14 failures with trimethoprim-sulphamethoxazole, 11 cases were followed up and treated

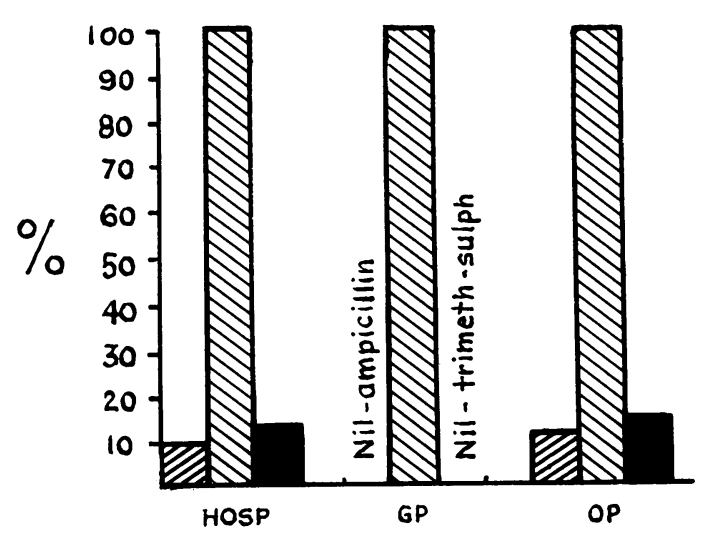

Fig. 1 The percentages of strains which were resistant to the three drugs in the beginning.

$\mathbb{Q}$ Ampicilin,

$\mathbb{N}$ Sulphonamide with ampicillin with excellent results, whereas oue of nine failures with ampicillin, six cases were followed up and treated with trimethoprim-sulphametho xazole with only two cases cured.

\section{Discussion}

From Figure 1 it becomes quite apparent that insofar as in-vitro sensitivity is concerned, the combination of trimethoprim-sulphamethoxazole appears to bemore effective than sulphonamide alone and as effective as ampicillin in urinary tract infections $\vec{\omega}$ In the comparative study between these three anti biotics in the treatment of urinary tract infections the combination was shown to be the best (Reevesiv et al, 1969). It has also been claimed that this comos bination was effective even when the strains werej resistant to sulphonamide (Grüneberg and Kolbe,, 1969). From Figure 2 it appears that this assumption is not true in cases of Streptococcus faecalis infec- tions. In this series, 14 strains of Streptococcuse faecalis became resistant to this potent combina- $\vec{D}$ tion, possibly due to two reasons. First, they were resistant to sulphonamide to start with and, second N the treatment had to be continued for more than two weeks. These factors may have helped sulphona mide-resistant strains to multiply selectively evens with the combination of trimethoprim. It is sugo gested that ampicillin is still the drug of choice in urinary tract infection due to Streptococcus faecalis? and trimethoprim-sulphamethoxazole should no $\overrightarrow{\vec{E}}$ be used in these cases for more than two weeks? Rotational therapy with other antibiotics to which the organisms are sensitive might be worthwhile

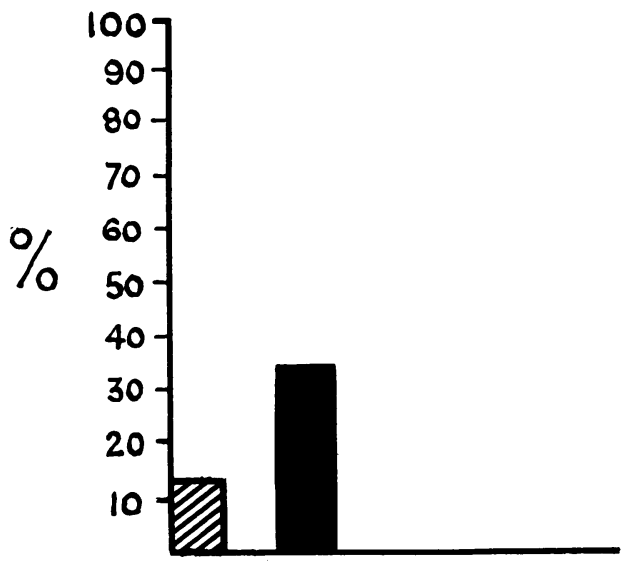

Fig. 2 The percentages of failure with ampicillin and trimethoprim-sulphamethoxazole therapy compared.

Trimethoprim-sulphamethoxazolอ 
I am grateful to Dr J. Kohn, senior consultant pathologist, for his helpful advice in preparing this article, and to all the consultants who allowed me to study these cases under their care.

\section{References}

British Medical Journal (1969). Leading Article. Trimethoprim in the urinary tract. Brit. med. J., 1, 525-526.

Brodie, J., Macqueen, I. A., and Livingstone, D. (1970). Effect of Trimethoprim-sulphamethoxazole on typhoid and salmonella carriers. Brit. med. J., 3, 318-319.

Bushby, S. R. M. (1969). Combined antibacterial action in vitro of trimethoprim and sulphonamides. Postgrad. med. J., 45, (Supp. Nov.), 10-18.

Darrell, J. H., Garrod, L. P., and Waterworth, P. M. (1968). Tri- methoprim: laboratory and clinical studies. J. clin. Path., 21, 202-209.

Farid, Z., Hassan, A., Wahab, M. F. A., Sanborn W. R., Kent, D. C., Yassa, A., and Hathout, S. E. (1970). Trimethoprimsulphamethoxazole in enteric fevers. Brit. med. J., 3, 323-324.

Grüneberg, R. N., and Kolbe, R. (1969). Trimethoprim in the treatment of urinary infections in hospital. Brit. med.J., 1, 545-547.

Hughes, D. T. D. (1969). Single-blind comparative trial of trimethoprim-sulphamethoxazole and ampicillin in the treatment of exacerbations of chronic bronchitis. Brit. med. J., 4, 470-473.

Kamat, S. A. (1970). Evaluation of therapeutic efficacy of trimethoprim-sulphamethoxazole and chloramphenicol in enteric fever. Brit. med. J., 3, 320-322.

Reeves, D. A. Faiers M. C., Pursell, E. E., and Brumfitt, W. (1969). Trimethoprim-sulphamethoxazole: comparative study in urinary infection in hospital. Brit. med. J., 1, 541-544.

Waterworth, P. M. (1969). Practical aspects of testing sensitivity to trimethoprim and sulphonamide. Postgrad. med. J., 45, (Suppl. Nov.), 21-29.

\section{Reports and Bulletins prepared by the Association of Clinical Biochemists}

The following reports and bulletins are published by the Association of Clinical Biochemists. They may be obtained from The Administrative Office, Association of Clinical Biochemists, 7 Warwick Court, Holborn, London, WC1R 5DP. The prices include postage, but air mail will be charged extra. Overseas readers should remit by British Postal or Money Order. If this is not possible the equivalent of $50 \mathrm{p}$ is the minimum amount that can be accepted.

\section{SCIENTIFIC REPORTS}

3 Automatic Dispensing Pipettes. An assessment of 35 commercial instruments 1967 P. M. G. BROUGHTON, A. H. GOWENLOCK, G. M. WIDDOWSON, and K. A. AHLQUIST $85 p(\$ 2)$

4 An Evaluation of five Commercial Flame Photometers suitable for the Simultaneous Determination of Sodium and Potassium March 1970 P. M. G. BROUGHTON and J. B. DAWSON $85 \mathrm{p}(\$ 2)$

\section{SCIENTIFIC REVIEWS}

1 The Assessment of Thyroid Function March 1971 F. V. FLYNN and J. R. HOBBS $62 \frac{1}{2} \mathrm{p}(\$ 1.50)$

2 Renal Function Tests Suitable for Clinical Practice January 1972 F. L. MITCHELL, N. VEALL, and R. W. E. WATTS $62 \frac{1}{2} \mathrm{p}(\$ 1.50)$

\section{TECHNICAL BULLETINS}

9 Determination of Urea by AutoAnalyzer November

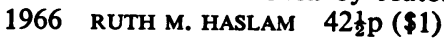

11 Determination of Serum Albumin by AutoAnalyzer using Bromocresol Green October 1967 B. E. NORTHAM

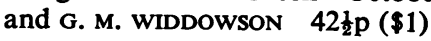

13 An Assessment of the Technicon Type II Sampler Unit March 1968 B. C. GRAY and G. K. MCGOWAN $42 \frac{1}{2} \mathrm{p}(\$ 1)$

14 Atomic Absorption Spectroscopy. An outline of its principles and a guide to the selection of instruments May 1968 J. B. DAWSON and P. M. G. BROUGHTON $42 \frac{1}{2} p(\$ 1)$

4
15 A Guide to Automatic Pipettes (2nd edition) June

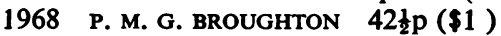

16 A Guide to Automation in Clinical Chemistry May

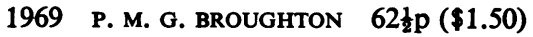

17 Flame Photometers (2nd edition) 1969 P. WILDING $62 \frac{1}{2} \mathrm{p}(\$ 1.50)$

18 Control Solutions for Clinical Biochemistry (4th edition) March 1970 P. M. G. BROUGHTON $62 \frac{1}{2} \mathrm{p}$ (\$1.50)

19 Spectrophotometers. A comparative list of low-priced instruments readily available in Britain May 1970 C. E. WILDE and P. SEWELL $62 \frac{1}{2} \mathrm{p}(\$ 1.50)$

20 Quantities and Units in Clinical Biochemistry June

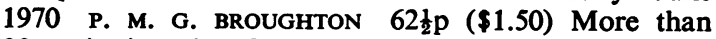
30 copies in units of 10 at $20 p$

21 Filter Fluorimeters: A comparative list of 18 instruments September 1970 H. BRAUNSBERG and S. S. BROWN 62 $\frac{1}{2} \mathrm{p}(\$ 1.50)$

22 Bilirubin standards and the Determination of Bilirubin by Manual and Technicon AutoAnalyzer Methods. January 1971 BARBARA BILLING, RUTH HASLAM, and N. WALD $62 \frac{1}{2} \mathrm{p}(\$ 1.50)$

23 Interchangeable Cells for Spectrophotometers and Fluorimeters September 1971 E. S. BROWN and A. H. GOWENLOCK $62 \frac{1}{2} \mathrm{p}(\$ 1.50)$

24 Simple Tests to Detect Poisons March 1972 B. w. MEADE et al. $\quad 62 \frac{1}{2}(\$ 1.50)$ 